\title{
A Selvagem Criação do Direito - Um Diálogo Imaginário entre Luis Alberto Warat e Deleuze/ Guattari sobre a Semiótica Jurídica
}

\author{
The Wild Creation of Law - An Imaginary Dialogue Between Luis Alberto \\ Warat and Deleuze/Guattari about Law's Semiotics
}

\section{Leonardo Monteiro Crespo de Almeida ${ }^{1}$ \\ ${ }^{1}$ Faculdade de Direito do Recife, Recife, PE, Brasil}

\begin{abstract}
Resumo: O presente artigo pretende estabelecer um diálogo entre o projeto de Luis Alberto Warat referente a uma semiótica jurídica crítica, que escape de certos reducionismos presentes na epistemologia jurídica do século $\mathrm{XX}$, e algumas das considerações de Deleuze/Guattari sobre a semiótica presentes na obra Mil Platôs. Utilizando-se de uma literatura secundária que constrói uma ponte entre a filosofia de Deleuze - e de Deleuze/Guattari - com o Direito, conclui-se esta leitura situando ambas as perspectivas como reflexões filosóficas sobre o que há de inusitado e de criativo no direito em detrimento de uma investigação sobre a verdade e as condições de possibilidade do conhecimento científico do direito, dois elementos recorrentes nas antigas epistemológicas do direito.
\end{abstract}

Palavras-chave: Warat. Semiótica. Deleuze. Guattari.
Abstract: This article intends to establish a dialogue between Luis Alberto Warat's project of a critical semiotics of law, one that avoids the common reductionisms of the legal epistemology from the beginning of the twentieth-century, and a few remarks of Deleuze/Guattari regarding semiotics. We take as our main reference the works of Deleuze and Guattari's scholars that read them within the framework of legal theory, our conclusion is that the authors, Warat and Deleuze/Guattari, develop philosophical centered on the creation and the uncanniness of Law instead of them being concerned with truth and the conditions of possibility of the scientific legal knowledge, two common features of earlier legal epistemological concerns.

Keywords: Warat. Semiotic. Deleuze. Guattari.

Recebido em: 04/10/2018

Revisado em: 02/09/2019

Aprovado em: 11/12/2019 


\section{Introdução}

Luis Alberto Warat dedicou as primeiras páginas de sua obra "O Direito e sua linguagem" à análise de duas abordagens fundamentais da semiótica, a de Ferdinand Saussure e a de Charles Sanders Peirce. Em sua leitura, ambos os autores se mostrariam presos a um formalismo científico capaz de construir uma sobreposição entre um campo do saber sobre o outro: a semiologia, enquanto ciência dos signos, é uma linguagem sobre outras linguagens, vindo a extrair delas as suas próprias categorias de análise. Cria-se um abismo entre a metalinguagem abstrata, formal e desinteressada, e as linguagens-objeto a que ela pretende analisar e também disciplinar.

Essas restrições acabariam por desconsiderar a complexidade das práticas que envolvem a semiologia, sobretudo no que se refere à demarcação e à articulação dos discursos, assim como ignorar que a fala e demais formas de expressão linguísticas ocorrem em contextos institucionais que, ao mesmo tempo em que favorecem determinadas possibilidades de expressão, tolhe outras. A complexa relação entre discurso e poder, por exemplo, é perdida quando se restringe a semiologia a uma metalinguagem científica.

No fundo, a teoria geral do direito - e falar nesse campo implica sempre conceber a possibilidade de um conhecimento científico sobre o direito - mantém-se como uma espécie de metalinguagem cuja linguagem-objeto a ser esclarecida e disciplinada é aquela que envolve a própria autocompreensão dos juristas que tomam parte em um campo muito específico e profundamente institucionalizado do social. Semelhante ponto acaba por aproximar Warat de alguns pontos estabelecidos por Gilles Deleuze e Félix Guattari em Mil Platôs.

Outro ponto de conexão é a preocupação com a teoria dos atos de fala e com a filosofia da linguagem ordinária. Assim como Warat, que dedica todo o capítulo terceiro da obra $O$ Direito e sua linguagem a uma análise da filosofia da linguagem ordinária, Deleuze/Guattari trataram de assimilar algumas das suas noções, sobretudo aquelas advindas de J. L. Austin, nas suas reflexões (DELEUZE; GUATTARI, 2002, p. 14-16). 
A conexão entre performatividade e linguagem é estabelecida pelos autores logo de início. Pode-se ver uma passagem que provavelmente Warat concordaria:

As palavras não são ferramentas; mas damos às crianças linguagem, canetas e cadernos, assim como damos pás e picaretas aos operários. Uma regra de gramática é um marcador de poder, antes de ser um marcador sintático. A ordem não se relaciona com significações prévias, nem com uma organização prévia de unidades distintivas, mas sim o inverso. (DELEUZE; GUATTARI, 2002, p. 12)

Para essa análise, esta abordagem no que diz respeito à literatura primária, no que concerne a Luis Alberto Warat, fora centrada na série dos três livros de introdução ao direito e a obra o direito e a sua linguagem, uma vez que neles a nossa discussão - e as preocupações desse artigo - encontram-se explícitas. Nossa leitura de Deleuze/Guattari foi organizada sobre três tipos específicos de literatura: a primária, e aqui nós nos detivemos nos Mil Platôs pelo desenvolvimento dos conceitos que se optou por examinar e também pelas discussões levantadas em torno da semiótica que essa obra traz; uma literatura secundária que se desenvolve no campo jurídico e que cria conexões entre Deleuze/Guattari e a prática do direito, a exemplo de Jamie Murray e James MacLean; por fim, e de menor importância se comparada às duas primeiras, uma literatura secundária voltada para o desenvolvimento das ideias dos autores no próprio campo da semiótica.

$\mathrm{O}$ desenvolvimento do artigo se divide em três partes. Na primeira será analisado mais detidamente o projeto de uma semiologia do poder e a sua conexão com a epistemológica jurídica a partir das considerações de Warat. Em seguida, será feita uma abordagem sucinta, em consideração aos limites deste artigo, sobre a maneira como Deleuze/Guattari abordagem a semiótica.

Por fim, na terceira seção, apresenta-se como a perspectiva de Deleuze/Guattari pode contribuir para as considerações de Warat sobre semiótica e epistemologia jurídica crítica de duas maneiras: enfatizando a rejeição à pretensão epistemológica pela determinação da especificidade 
fenômeno jurídico e por uma ênfase na criação, no novo e inusitado em detrimento da verdade e da validade dos saberes. Chama-se essa criação de selvagem porque não obedece nem fundamento, nem pode ser contida por uma finalidade pré-estabelecida.

\section{Semiologia do Poder e Linguagem Jurídica na Perspectiva de Luis Alberto Warat}

Nos livros que compõem a sua introdução ao estudo do direito, várias são as sessões em que Warat se dispõe a examinar os meandros do poder na dinâmica das várias práticas jurídicas. No capítulo quinto do primeiro livro que compõe a sua série de introdução ao direito, após examinar inúmeras abordagens de interpretação das leis, Warat observa como a neutralidade, que caracterizaria a investigação epistemológica e que serviria para afastar a arbitrariedade da política, contribui para o fortalecimento dessa última (WARAT, 1994, p. 92).

Se a ideia dos métodos interpretativos consiste em trazer para a interpretação dos elementos normativos do direito a objetividade e o rigor associado ao universo de referências científicos, esses métodos terminam ocultando as estratégias de dominação inseridas no desdobramento das práticas jurídicas. Métodos, nesse contexto, antes servem para construir e impor verdades e estruturas argumentativas de legitimação voltadas para a difusão inquestionável daquelas verdades.

Uma das tarefas centrais do tipo de semiologia proposta por Warat é conceber uma epistemologia jurídica comprometida em desocultar as estratégias de dominação que a preocupação formalista, que ele enxerga nos estudos epistemológicos, outrora tratava de ocultar, alimentar e disseminar: a epistemologia como cúmplice do poder. A sua preocupação recai na relação entre os discursos de um determinado campo e as condições extradiscursivas que permitem, fortalecem ou obstruem a sua circulação.

Os vários processos de significação, que ocorrem a partir de uma estrutura institucional, traduzem certas estratégias de determinados grupos e segmentos sobre outros grupos, ou seja, constituem prática política. 
A prática científica precisa reconhecer esse jogo de forças no estudo das interações sociais que constituem as significações nos vários espaços do social:

Neste sentido cabe afirmar que a explicitação das condições que possibilitam a produção das ciências sociais evidencia a interrelação das forças forjadas de domínios de conhecimentos discursivos e extra-discursivos, e de sujeitos, como efeitos da política, da ideologia e das significações acumuladas. O pressuposto filosófico que deve sustentar a epistemologia das significações é semiológico, já que com ele se busca orientar a prática científica para um plano de análises que permita o conhecimento da interação social como acontecimentos significativos (discursivos e extra-discursivos). (WARAT, 2002, p. 307-308)

Interpretações e decisões judiciais obtêm a aceitabilidade necessária para produzir efeitos dentro - e por meio - da esfera institucional em que se encontram. Por isso a insistência de Warat em reiterar que não se deve pensar apenas no discursivo, mas também em todos os elementos que se encontram em seu entorno, e, de certo modo, concorrem para a produção dos seus efeitos, que ele nomeia o extradiscursivo.

O objetivo de Warat consiste em romper com o formalismo que ele percebe como recorrente na epistemologia jurídica. Não pretende com isso "purgar" os vários discursos políticos dos efeitos de estereotipação e da construção de tópicos através, antes ressaltar a presença desses efeitos no discurso uma vez que já não compreende mais o discurso como prática restrita à significação: é também prática política (WARAT, 1995, p. 101). Por isso, a insistência do autor em que um determinado discurso não pode proporcionar a chave para a própria inteligibilidade: há sempre algo mais implicado naquilo que o discurso expressa do que a sua própria lógica interna visa determinar.

Um momento de sua obra em que essa indagação se torna mais clara reside na sua análise das implicações políticas da noção de pureza no contexto da teoria pura do direito de Kelsen. Um dos efeitos desse procedimento epistemológico consiste em erguer uma distinção, no plano da 
ciência do direito, entre o jurídico e o político. Tratar-se-ia de um procedimento necessário para a constituição da ciência como metalinguagem, o que Warat já havia mencionado em sua análise das duas abordagens fundantes da semiologia. O que se afirma é resumido pelo autor da seguinte forma:

A teoria pura do Direito, ao ser reduzida a um conceitualismo presente tanto no idealismo crítico como no positivismo lógico, consegue eliminar de sua problemática a discussão sobre os fatores co-determinantes da realidade jurídica, como também sobre o papel social e político do Direito e as dimensões ideológicas dos diversos discursos jurídicos enquanto prática jurídica concreta. (WARAT, 2002, p. 132)

A influência kantiana leva Kelsen, por meio de procedimentos não muito distantes daqueles já presentes no criticismo kantiano, a um esclarecimento dos critérios metodológicos que permitiriam a demarcação e a autonomia do conhecimento jurídico. Os princípios a priori, tanto metodológicos quanto epistemológicos, vão tratar de moldar o formato da teoria pura. As categorias a priori kantianas, nos diz Warat (2002, p. 135), refletem condições de significação desvinculadas da experiência empírica. São condições de possibilidade. Também Kelsen busca estabelecer as condições formais e necessárias do conhecimento jurídico, especialmente a sua estrutura normativa e conteúdo deôntico (WARAT, 2002, p. 135).

A consequência mais problemática do posicionamento kelseniano, na leitura de Warat, consiste no estabelecimento da cisão entre produção do saber jurídico pelos atores que integram o espaço institucional do direito e o conhecimento científico que terá como objeto de sua investigação esses mesmos valores. Quer dizer, ao mesmo tempo em que a ciência do direito necessita extrair as suas categorias e conceitos do saber produzido pelos juristas, ela precisa manter um distanciamento para não se confundir com o seu objeto.

Considerando que a significação das normas jurídicas, no entendimento que possui Warat do normativismo kelseniano, ocorre por meio das relações de associação desenvolvidas a partir da estrutura do ordenamen- 
to jurídico positivo, ocorre que a significação acaba sendo efeito, direto e indireto, da própria estrutura normativa. O que Warat pretendia, nesse ponto, não é a negação do projeto kelseniano, mas em ressaltar também a presença dos fatores extrassistemáticos na produção do sentido das normas jurídicas. A partir daí também se poderia vir a esclarecer o caráter institucional, político e social que se faz presente na produção de sentido das normas.

Uma outra consequência, que advém dos postulados de purificação, consiste no isolamento de certas indagações referentes à produção das próprias normas jurídicas. Considerando a adoção de uma perspectiva estritamente descritiva, trazer para si o momento de produção das normas jurídicas implicaria adentrar em um território com o qual a teoria pura não pode se misturar: o da política jurídica. Em síntese, na concepção de Warat, Kelsen buscou evitar uma confusão entre a perspectiva epistemológica, já caracterizada como metalinguagem, e a sua linguagem-objeto, representada pelas decisões judiciais tal como os juízes as tomam em seus contextos institucionais (WARAT, 2002, p. 151).

Para ele, então, o inconveniente consiste não em esclarecer a influência do contexto social na produção das próprias categorias que informam o conhecimento jurídico. Se, por um lado, as indagações metodológicas da teoria pura do direito permanecem pertinentes, estas precisam ser complementadas através de uma dimensão crítica trazida para dentro - e não mais deixada de fora - do próprio projeto epistemológica.

Considerando as características que acompanham as reflexões epistemológicas positivistas no direito, Warat enxerga na semiologia um campo especial de investigação para o projeto de uma epistemologia crítica. Entre outras razões, esse projeto epistemológico quer ressaltar como a linguagem toma parte do processo de estereotipação das significações a partir da redução da complexidade social.

Um aspecto pertinente, no contexto da epistemologia pretendida por Warat, é o modo como ele põe em questão um certo empirismo restrito que integra as epistemologias associadas ao positivismo. Por empirismo restrito é preciso apontar o privilégio da realidade sensível na determinação das conceitualizações do conhecimento. Uma consequência, 
por exemplo, seria um maior peso epistemológico dos enunciados das ciências da natureza em detrimento a outros campos do saber cujos objetos integram o domínio simbólico da sociedade, a exemplo das ciências humanas. O recorrendo à semiologia, Warat pretende expandir o horizonte da investigação epistemológica:

Uma suposição fundamental para o desenvolvimento da epistemologia das significações é dado pelo abandono da idéia de que o conhecimento se refere unicamente à conceitualização das significações emergentes da realidade sensível. Ademais o conhecimento não versa apenas sobre a realidade concreta (não é um reflexo fiel dela mesma), e sim sobre o sistema de significações que, sobre ela, as distintas variações do saber acumulado podem construir. (WARAT, 2002, p. 313-314)

$\mathrm{Na}$ perspectiva em que Warat a concebe, a epistemologia jurídica contempla também uma análise crítica dos processos linguísticos de constituição simbólica do campo institucional dos juristas. Sendo assim, a aproximação com as chamadas ciências humanas, outrora deixadas de lado por projetos epistemológicos que admitiam como padrão científico as ciências da natureza, torna-se uma característica fundamental do seu projeto epistemológico.

Revisitando um lugar comum encontrado em Nietzsche e em autores influenciados pela sua obra, o lugar da fala é sempre a abertura de uma perspectiva, de um modo. A investigação epistemológica proposta por Warat pretendeu trazer à tona esse detalhe na análise do conhecimento jurídico a partir de uma incursão crítica pela teoria do direito, e com isso ressalta as múltiplas maneiras de constituição do fenômeno jurídico e as possibilidades, inclusive inatualizadas, que aí se encontram em jogo.

\section{Pequena Consideração sobre Semiótica e Poder sob a Perspec- tiva de Gilles Deleuze e Félix Guattari}

As reflexões sobre a linguagem na obra dos dois autores, especialmente naquelas escritas em colaboração, não possuem uma organização 
sistemática, o que nos obriga a construir associações entre os conceitos que melhor servem ao desenvolvimento de nossas preocupações teóricas. Um primeiro ponto a ser ressaltado nesta abordagem é a relação os discursos e as instituições. Em Mil Platôs, tem-se a ideia de que todo ato de fala é também um ato de poder na medida em que ocorre em espaços envolvidos por regras e estruturas que limitam, permitem ou proíbem a sua expressão. Palavras servem a algo: compõem e modificam o mundo material em que nós nos encontramos. A sua dimensão sintática é precedida por essa preocupação operacional/pragmática:

A linguagem não é a vida, ela dá ordens à vida; a vida não fala, ela escuta e aguarda. Em toda palavra de ordem, mesmo de um pai a seu filho, há uma pequena sentença de morte - um Veredito, dizia Kafka. O difícil é precisar o estatuto e a extensão da palavra de ordem. Não se trata de uma origem da linguagem, já que a palavra de ordem é apenas uma função-linguagem, uma função coextensiva à linguagem. (DELEUZE; GUATTARI, 2002, p. 13)

Essa passagem indiretamente dialoga com a preocupação de Warat em expandir os limites da investigação epistemológica para considerar também a maneira como os sistemas de conceitos moldam a percepção da realidade material que se pretende explorar. De maneira muito próxima ao que se observa na reflexão de Warat, também se encontra em Deleuze/ Guattari uma relação entre semiótica e poder, mas concebida a partir de um itinerário teórico completamente diferente. Vamos explorá-lo agora.

É essa linha de raciocínio básica que atravessa a incursão dos autores pela semiótica consiste na seguinte: a língua necessariamente traz dentro de si possibilidades inexploradas, uma dimensão virtual, de excesso e que permanece inatual. Como será mencionado nos Mil Platôs e em outros momentos da filosofia do próprio Deleuze, não se deve conceber a relação entre virtual e real em termos de oposição (DELEUZE; GUATTARI, 2002, p. 43).

A oposição aceitável ocorre entre a contínua variação das relações e dos seus elementos constitutivos, e a determinação atual das relações tal qual elas se fazem mostrar. As relações possíveis sempre excedem aque- 
las que já se encontram atualizadas e disponíveis. Percebe-se esse aspecto nos Mil Platôs quando Deleuze/Guattari reiteram as múltiplas desterritorializações que fazem emergir línguas e práticas menores (como a apropriação de Kafka do alemão) e devires que extrapolam os limites estabelecidos pelas estruturas (SILVA et al., 2013, p. 13). Será associada agora essa preocupação a uma investigação que adentra no terreno mais particular da semiótica jurídica e cujos marcos iniciais, neste trabalho, foram fornecidos por Warat.

Em seu artigo, Deleuze \& Guattari's Intensive \& Pragmatic Semiotic of Emergent Law, Jamie Murray ressalta que se pode pensar uma semiótica jurídica através das considerações gerais sobre a semiótica que os autores realizam em sua obra. Essa semiótica é associada, nos diz Murray, à ontologia da emergência que os autores também desenvolvem. Mas o que pretende este conceito de emergência? Murray nos aponta:

O campo da emergência é teorizado como um campo de forças em que processos intensivos de emergência e auto-organização operam sobre a matéria. Esses processos são imanentes à matéria, sendo uma relacionalidade exterior entre elementos heterogêneos em movimento que produzem um excesso que remete às interações constitutivas desses $\operatorname{processos}^{1}$. (MURRAY, 2007, p. 8)

O que eles estão explorando nesse ponto é como em uma dada totalidade, composta de elementos diversos, ao organizar a si mesma, pode produzir algo novo e distinto. Pensar a emergência, portanto, significa pensar como o novo e distinto podem surgir a partir de uma totalidade já estruturada. Sendo o novo for apenas o efeito das leis e comportamentos estabelecidos, o que se tem é mais uma consequência do que já se fazia presente a partir na totalidade. O novo, pelo contrário, emerge da totalidade ao mesmo tempo em que não pode ser completamente explicado pelas

\footnotetext{
${ }^{1}$ No original: "The field of emergence is theorised as a field of forces where intensive process of emergence and self-organisation operate in matter. These processes are immanent to matter, and it is an exterior relationality between heterogeneous elements in movement that produces an excess of coming together in interacting that constitutes these processes" (Tradução livre).
} 
relações de causalidade entre os elementos existentes - e por isso Murray fala em quase-causa (MURRAY, 2007, p. 9 e ss.).

Uma reflexão jurídica a partir de uma ontologia da emergência não estaria preocupada, segundo Murray, na produção de sentidos que operassem através da validação realizada por um determinado sistema, a exemplo da inserção de um conceito em um ordenamento jurídico ou de sua reprodução por uma certa doutrina, mas promover intervenções interessantes que desestabilizem as operações. O importante é cultivar o novo através da provocação de eventos cuja novidade produza interesse e um choque para o pensamento, algo que confronte maneiras de ser e pensar pré-existentes ao evento (MURRAY, 2007, p. 28).

O caos e a complexidade dinâmica das relações dos sistemas de comunicação compõe, mesmo que em parte, a base da reflexão teórica de James MacLean, outro leitor de Deleuze na área do Direito. Em sua obra acerca da decisão judicial através da perspectiva filosófica de Deleuze/ Guattari, Rethinking Law as Process, James MacLean desenvolve a temática da seguinte forma:

Conforme a teoria do caos, cada sistema complexo é único, com interações múltiplas e loops de feedback entre seus elementos. Eles são dinâmicos, o que significa que existem em ambientes mutáveis e que, por isso mesmo, exigem que eles se adaptem. Eles precisam evoluir, e quando o fazem, tornam-se com isso mais complexos. Aqui, cada elemento responde a uma informação local e não a um sistema mais amplo de informação, sendo as interações não-lineares; quer dizer, elas possuem múltiplos componentes que raramente são explicados em relações simples de causa e efeito. (MACLEAN, 2012, p. 148) $)^{2}$

\footnotetext{
${ }^{2}$ No original: "According to Chaos Theory, each complex system is unique, with multiple interactions and feedback loops between elements. They are dynamic, which means that they exist in changing environments and therefore need to be adaptable. They evolve and, as they do, become more complex. Here, each element responds to local information and not to broader system information, and interactions are non-linear; that is, they contain multiple components that are rarely explainable in simple cause and effect relations" (Tradução livre).
} 
Em que medida os processos descritos por MacLean poderiam ser associados a uma reflexão sobre o signo? O ponto de partida precisa ser a concepção deleuzeana de signo que, como se observará, não se encontra desassociada da vida e dos seus eventos. Pensar o signo implica situar caminhos e possibilidades para o seu desenvolvimento. Um signo não se explica, antes constrói uma abertura para a colocação da pergunta sobre a sua explicação, por isso pensá-los é também pensar os processos de formação da subjetividade, seja a de enunciação ou mesmo aquela que reveste o sujeito de direito que protesta, a partir de um espaço determinado:

Signos implicam em modos de viver, possibilidades de existência, eles são sintomas da vida que pressionam adiante ou se retraem [...] Existe uma conexão profunda entre signos, eventos, a vida e o vitalismo: o poder da vida não-orgânica que pode ser encontrado na linha que é desenhada, uma linha da escrita, uma linha da música³ (DELEUZE, 1995, p. 143)

Os modos de vida, portanto, podem ser expandidos ou retardados, promovidos ou rechaçados no espaço em que se encontram. Esses modos não se situam apenas a partir dos eventos, mas como cada evento é desdobrado em linhas cujo desenvolvimento não se sabe ao certo o que podem fazer e/ou onde podem nos levar. O devir escapa à determinação, mas escapar não significa fugir para fora de algo, mas vazar, destoar. Jay Conway (2010, p. 97-98) observa que inexiste sistema social sem esses "vazamentos". A captura e a determinação normativa inscrita na cultura e reproduzida pelas instituições jamais é plena - e isso é ainda mais intenso considerando um campo de saber que se percebe como estritamente normativo.

A partir dessa consideração sobre o regime dos signos, o que se tem é uma dupla dimensão em que a materialidade das práticas sociais, instituições e rituais se entrelaçam com a imaterialidade dos signos e dos atos

\footnotetext{
${ }^{3}$ No original: "Signs imply ways of living, possibilities of existence, they're symptoms of life gushing forth or drawing away...There's a profound link between signs, events, life and vitalism: the power of non-organic life that can be found in a line that's drawn, a line of writing, a line of music" (Tradução livre).
} 
de fala. A utilização de um signo precisa ser considerada em seu contexto, especialmente no que concerne às forças não-discursivas que estabelecem a organização e as condições pelas quais se pode proferir enunciados considerados válidos nesses contextos.

Essas condições, ao mesmo tempo em que situadas pelas palavras de ordem que compõem - e almejam formatar - o campo de emergência, são também modificadas pelo próprio devir interno do social, ou seja, pelos movimentos desestabilizadores presentes no social. Deleuze/Guattari compreendem as palavras de ordem da seguinte maneira:

Chamamos de palavras de ordem não uma categoria particular de enunciados explícitos (por exemplo, no imperativo), mas a relação de qualquer ou de qualquer enunciado como pressupostos implícitos, ou seja, com atos de fala que se realizam no enunciado, e que podem se realizar apenas nele. As palavras de ordem não remetem, então, somente aos comandos, mas a todos os atos que estão ligados aos enunciados por uma "obrigação social". Não existe enunciado que não apresente esse vínculo, direta ou indiretamente. (DELEUZE; GUATTARI, 2002, p. 16)

O embate entre a estabilidade das relações em meio a forças que constantemente as desestruturam e as deslocam é novamente reiterada pelos autores. Andreas Philippopoulos-Mihalopoulos concebe essa tensão a partir de dois conceitos que, mais adiante, nos ajudam a compreender certas nuances do funcionamento do direito moderno: logos e nomos (PHILIPPOPOULOS-MIHALOPOULOS, 2012, p. 98). O logos organiza compartimentaliza o espaço a partir de fronteiras e demarcações, operando por generalidade; o nomos, por sua vez, aponta para uma lei sem fronteiras e limites definidos, tendendo à complicação dos espaços estabelecidos. Philippopoulos-Mihalopoulos nos lembra que, na concepção deleuzeana, o movimento da matéria remete simultaneamente à ordem e ao caos (PHILIPPOPOULOS-MIHALOPOULOS, 2012, p. 94).

Retorna-se ao ponto inicial da incursão de Deleuze/Guattari pela semiótica: pensar a emergência do novo e do inaudito por meio do campo de emergência. Se, como observado no início desta seção, ao mesmo 
tempo em que o novo não surge ex nihilo, ele também não pode ser um produto das relações entre os elementos constitutivos do próprio campo. A tensão entre logos e nomos permite a emergência do novo enquanto consequência de transformações não-lineares pertencentes ao campo. Essa emergência não significa o surgimento de um novo fundamento - ou seja, um novo começo - muito menos a chegada em algum lugar predefinido, portanto, a um fim já determinado. Nem começo, nem fim, as transformações se desdobram continuamente nas direções mais variadas sem, no entanto, constituir algum fundamento ou se fixar a um destino (DELEUZE; GUATTARI, 2004, p. 32).

Se os signos apontam para uma série de possibilidades e modos de vida a partir da materialidade do campo social - e por materialidade, mais uma vez, pode-se pensar as práticas sociais e as instituições que as envolvem -, as transformações que atingem essa materialidade impulsionam a elaboração de novos signos, modificando também os já existentes: nomos e logos se associam. A repetição contínua de cada palavra de ordem, que outrora se mostrava distinta, implica em torná-la redundante, ou mesmo estereotipada, sim, mas também abrange a renovação e a presença possibilidades ainda inexploradas:

Cada palavra de ordem fora antes uma nova emergência, e em cada uma de suas repetições, mesmo quando estritamente associada aos imperativos do poder, faz com que o evento da emergência seja indexado e a sua repetição redundante re-potencializada através da persistência do campo de emergência. (MURRAY, 2007, p. 19) ${ }^{4}$

Um slogan ou um enunciado normativo validado por meio das múltiplas práticas sociais e das instituições moldam e organizam esse contexto, criando com isso espaço para novos arranjos e estados de coisas. Pode vir a catalisar ou induzir o surgimento de novos eventos através da desestabilização daqueles que já sedimentados.

\footnotetext{
${ }^{4}$ No original: "Every order-word was once a novel emergence, and in each repetition, even when strictly in the imperatives of power, the event of emergence is indexed and the redundant repetition re-potentialised by the persistence of the field of emergence". (Tradução livre).
} 
As contínuas desestabilizações que o campo jurídico sofre ocorrem a partir da própria estrutura conceitual que integra as práticas presentes no sistema. Por isso os autores ressaltam a auto-organização desses processos: as sucessivas rupturas ocorrem sobre algo estabelecido, a exemplo da estrutura conceitual, e rapidamente constroem, sobre ela, uma outra base, iniciando com isso novo processo a partir do anterior. São essas interações circulares, mas que não seguem padrões determinados e previsíveis, que MacLean outrora apontou como loop de feedbacks. Em O Que é a Filosofia, os autores apresentam uma passagem sobre a criação conceitual e distinção entre interno/externo que o próprio conceito estabelece:

Mas o conceito não é dado, é criado, está por criar; não é forma do, ele próprio se põe em si mesmo, auto-posição. As duas coisas se implicam, já que o que é verdadeiramente criado, do ser vivo à obra de arte, desfruta por isso mesmo de uma autoposição de si, ou de um caráter autopoiético pelo qual ele é reconhecido. Tanto mais o conceito é criado, tanto mais ele se põe. O que depende de uma atividade criadora livre é também o que se põe em si mesmo, independentemente e necessariamente: o mais subjetivo será o mais objetivo, (DELEUZE; GUATTARI, 1997, p. 20)

Acontecimentos situados fora do universo de referências jurídicas contribuem - ou mesmo iniciam - transformações no campo jurídico que levem a reorganização de uma ou mais práticas assentadas. O surgimento de uma nova forma de disseminar o conhecimento, como a internet e novos protocolos que permitam o compartilhamento de arquivos, pode iniciar transformações que podem levar à reorganização de vários pressupostos nas áreas do direito penal e do direito autoral.

Se essas transformações vão proceder ou não dependerá da maneira como ambas as áreas as absorvem em sua estrutura conceitual específica. É preciso ponderar se compartilhar arquivos na internet é uma nova modalidade de furto, e com isso alargando o sentido usual para o termo 'furto', ou não será modificado porque a ação não é compatível com a definição legal de furto, devendo um novo tipo penal ser criado. A resposta é menos interessante do que o caráter incomum da situação problemática. 
Em ambos os casos, o evento demanda uma resposta jurídica, ao mesmo tempo paralisando a dinâmica usual do campo ao apresentar uma situação inusitada e problemática, como também operando novas transformações no campo. A mudança que desestrutura também propõe novas estruturas: a desterritorialização possui como seu complemento a reterritorialização (DELEUZE; GUATTARI, 2004, p. 69).

O par logos/nomos expõe a tensão que permeia a reflexão filosófica de Deleuze/Guattari e que se traz para uma abordagem do direito e de sua linguagem. Embora os conceitos jurídicos visem a estruturar uma realidade tomada como objeto de sua intervenção, essa realidade, dinâmica e complexa, reformula também a estrutura e abrangência inicial daqueles conceitos.

A relação entre o macro/estável, e o micro/instável é ilustrada por um outro par conceitual desenvolvido pelos autores: o molar e o molecular. Em um dos seus artigos em que recorre à filosofia dos autores para abordar a criação no direito, Marc Schuilenburg (2012, p. 125) descreve a relação entre esses dois conceitos da seguinte maneira:

O que eles estão argumentando, de fato, é que os dois níveis devem ser tratados como relativos a uma escala particular. Um exemplo simples disso seria o seguinte: podemos observar uma pessoa como uma identidade molar se estudarmos as suas crenças e desejos que a individualizam. Mas a pessoa pode ao mesmo tempo ser considerada no nível molecular com relação à organização que ela ou ele toma parte. De fato, o movimento do molecular se combina para produzir entidades molares que, posteriormente, reagem sobre o molecular, fazendo com que ele se transforme e se adapte ${ }^{5}$.

\footnotetext{
${ }^{5}$ No original: "Essentially what they are arguing here is that the two levels must be treated as relative to a particular scale. As a simple example of this, one can look at a person as a molar identity if studying the beliefs and desires out of which he or she individuates. But a person can at the same time be considered on a molecular level in relation to the organization he or she is a part of. In fact, the movement of the molecular combines to produce molar entities which in turn re-act on the molecular, forcing it to change and adapt". (Tradução livre).
} 
Essa pluralidade de perspectivas nos permite conceber a relação entre o logos e o nomos a partir das sucessivas transformações imanentes que operam no campo, e que nós aludimos mediante os conceitos de desterritorialização e reterritorialização. Por fim, embora a estrutura normativa do direito, que abrange a dogmática jurídica, seja mobilizada para a captura e organização dos eventos, estes se subtraem parcialmente a essa captura ao mesmo tempo em que produzem modificações na estrutura normativa do direito.

Compreendendo qualquer área da dogmática jurídica como um regime de signos, para além de descrições específicas e pontuais da realidade social, elas existem para possibilitar intervenções nessa realidade, ou seja, a dimensão pragmática antecede - e se sobrepõe - à dimensão sintático-semântica que compõem a forma da norma jurídica.

Entretanto, essa intervenção, que pode se mostrar sob a forma da organização de ações ou omissões em tipos (como no caso da tipicidade penal ou dos fatos geradores dos tributos), ela mesma é continuamente reorganizada nesse processo. Novos casos que, embora tragam consigo uma série de elementos que os tornem próximos da descrição usual de um tipo penal ou fato gerador, ainda assim podem expor dificuldades para a operacionalização das normas jurídicas disponíveis.

\section{O Encontro da Semiótica Jurídica de Warat com a Filosofia de Deleuze/Guattari}

Embora muitas das considerações de Warat sejam direcionadas ao positivismo jurídico, percebe-se que a preocupação do autor se detém na perspectiva epistemológica que envolve aquela perspectiva. $\mathrm{O}$ questionamento do normativismo de Kelsen, por exemplo, pretende ressaltar como a construção semântica da norma jurídica não pode ser restringida às relações que ocorrem entre os elementos constitutivos do ordenamento jurídico: a dimensão extradiscursiva precisa ser considerada ao lado da discursiva. Nela, o poder aparece como objeto de reflexão na forma de pressões políticas, vantagens econômicas ou outras formas simbólicas de 
dominação culturalmente enraizadas se interpõem à construção científica do objeto e/ou de um campo.

Então, não apenas as fronteiras que compõem a teoria do direito precisam ser interrogadas, como também uma vigilância epistemológica precisa ser estabelecida em torno da própria maneira com que os objetos que integram o campo jurídico são construídos. Por isso a insistência em trazer para o horizonte da reflexão epistemológica, um comprometimento crítico e um mapeamento mais complexo e diversificado da própria gênese dos conceitos jurídicos, daí a sua insistência em ressaltar o plano extradiscursivo na produção do conhecimento jurídico.

Ao discorrer sobre o seu itinerário intelectual, Warat revela a sua troca de uma visão de mundo jurídica, e que seria possível conceber como em termos estritamente normativos, por uma que conceba o direito através das múltiplas mediações que operam sobre o social (WARAT, 1995, p. 108). É por meio do reconhecimento da mediação sócio-histórica do jurídico que Warat repensa as pretensões positivas da semiótica e, na medida em que assim procede, encontra nela um fundamento para uma epistemologia crítica do direito.

Considerando a exposição realizada pelo autor de algumas das principais abordagens da linguagem no começo do século XX, a exemplo do estruturalismo de Saussure e da filosofia da linguagem ordinária de J. L. Austin, percebe-se já um distanciamento de Warat às concepções representacionistas da linguagem. Uma vez que ressalta o plano extradiscursivo dos enunciados e conceitos jurídicos, o que se busca ressaltar consiste na maneira com que os termos intervêm, constroem e transformam o estado de coisas que eles tomam como referência ao invés de atuarem como imagens dessa realidade.

As condições pelas quais esses atos podem ser validados remetem, por sua vez, aos contextos normativos e institucionais que os envolvem. Recorrendo à ontologia social de Cornelius Castoriadis, Warat observa como o conjunto de normas, valores e significações, na verdade, termina por construir um plano de sentido relativamente estável, posto ser apenas uma idealização, em meio ao caos do próprio real: 
Para existir, uma sociedade precisa ser instituída. A sociedade se mantém coesa recorrendo a criação de significações fantasmáticas que a instituem como totalidade: a instituição idealizada de normas, valores e significações que permitem enfrentar o caos do real, criando a subjetividade e o mundo que garante a potência reprodutiva do poder. (WARAT, 1995, p. 110-111)

É nesse contexto de discussão que Warat desenvolve a sua preocupação com a constituição das subjetividades através das práticas sociais e das relações de poder em que os sujeitos já se encontram implicados. Isso porque, muito provavelmente influenciado por Castoriadis e Antônio Negri, a problemática da instituição da sociedade passa pela ideia de autonomia e também de uma reconsideração da cidadania enquanto forma de subjetividade política compreendida como potência de liberação no interior dos limites autoestabelecidos da sociedade (WARAT, 1995, p. 108).

A cidadania, por exemplo, é um dos conceitos que vai possibilitar a Warat operar um entrelaçamento entre os domínios da política e do direito. Para isso, no entanto, dois pressupostos precisam existir: 1) Desassociar o direito a linguagem da obediência e do controle; 2) Conceber a semiologia jurídica como semiologia política. Analisemos os dois.

O primeiro ponto reflete a busca de Warat por uma compreensão mais abrangente do domínio jurídico. Reconhecendo a função institucional do direito positivo nas sociedades contemporâneas, ele reconsidera a persistente associação entre fenômeno jurídico e as várias formas de sujeição e técnicas de controle. Um dos pontos em que essa proposta se encontra ancorada consiste em conceber a cidadania como força jurídico-política importante na construção do direito positivo e das instituições que com ele se encontram associadas.

Um outro ponto, associado ao primeiro, residiria na constituição de novas formas de subjetividade decorrentes da vontade de autonomia e da construção de novos espaços simbólicos em uma dada formação social - e Warat menciona aqui o singular itinerário histórico da América Latina, distante do desenvolvimento social e histórico do mundo europeu (WARAT, 1995, p. 109 e ss.). 
O segundo ponto também reflete uma atitude crítica acerca do positivismo, agora tendo como alvo as suas pretensões epistemológicas: a pretensão de uma racionalização e sistematização do conhecimento jurídico ao mesmo tempo em que são isoladas as suas especificidades e condições de validade. Já se viu que, no que se refere à semiótica, é a preocupação metalinguística, aqui compreendida como linguagem sobre as linguagens na concepção de Saussure, que será questionada por Warat.

Observação semelhante será também estendida às pretensões da teoria geral do direito: o distanciamento e a pretensão formalista dessas teorias revelam uma pretensão similar de controle e delimitação das várias manifestações concretas do fenômeno jurídico. Em certo sentido, a pretensão de estabelecer os alicerces fundamentais para a reflexão jurídica: conceitos como norma jurídica, ordenamento, sanção, validade, contrafacticidade, compõem o que há de mais geral na investigação jurídica.

O conceito de palavras de ordem, relembremos, expressa uma relação entre a produção dos efeitos dos signos e o contexto institucional que eles tendem a operar. Essa operacionalização, porém, não é completamente circunscrita a uma relação de causalidade que, ao menos em tese, permitiria a determinação e o mapeamento dos seus efeitos. Existe sempre algo que excede - ou escapa - as determinações de uma estrutura, como um ordenamento jurídico particular, embora lhe seja crucial para a sua própria existência (PHILIPPOPOULOS-MIHALOPOULOS, 2011, p. 48 e ss.).

A preocupação conceitual que Warat delimita na teoria do direito pode ser repensada através de Deleuze/Guattari como um exercício contínuo de interrogação dos conceitos jurídicos por meio dos problemas que eles se encontram associados. Por isso, a distinção entre logos e nomos, entre o aberto e o fechado no direito, mostra-se pertinente. Ao mesmo tempo em que os conceitos fixam e organizam uma ordem normativa que funciona através da sobreposição que opera sobre casos particulares. As soluções desenvolvidas pelo jurista praticante operam através da articulação entre esses dois planos: a estrutura normativa do direito e um estado de coisas que, à luz daquela estrutura, percebe-se como um problema que aguarda uma prestação jurisdicional contingente. 
Por isso, concebe-se também o nomos pela transformação nas demarcações normativas estabelecidas: se a estrutura normativa do direito muda - e necessariamente precisa mudar - em face das múltiplas maneiras com que é atualizada em situações particulares, essas mudanças não ocorrem conforme planos fixados pela própria estrutura. Essa relação foi bem captada por Edward Mussawir em mais uma leitura sobre a filosofia de Deleuze e suas possíveis implicações a reflexão jurídica:

A única forma de seguirmos para além do Direito, Deleuze sugere, é através da 'jurisprudência' - uma criatividade prática que pertence às situações locais e aos casos - muito embora a própria jurisprudência não opere fora das leis e em alguma esfera abstraída dos princípios jurídicos padrões. Ela necessita de todas as leis, princípios jurídicos, juízos, etc para assim constituir o deserto do seu modo imanente de navegação. (MUSSAWIR, 2011, p. 3) ${ }^{6}$

Embora os textos abordados de Warat revelem que ele tinha uma boa noção do aspecto pragmático da linguagem jurídica, ele se preocupou pouco em examinar a maneira como as construções conceituais dos juristas, especialmente aquelas da dogmática, encontram-se associadas aos imperativos operacionais dos sistemas jurídicos. Warat ressaltou a pragmática ao mesmo tempo em que se esqueceu do pragmatismo - e por isso é difícil pensar através do seu projeto uma concepção prática e criativa da decisão judicial. Sabe-se que essa decisão não pode ser pensada somente em termos normativos, muito menos quando esses termos se encontram encerrados às fontes formais do direito, mas de que maneira aquela decisão escapa a uma construção lógica concebida em termos de silogismo, isso não fica claro.

Seguindo Mussawir, a intuição deleuzeana de uma decisão judicial que ao mesmo tempo que não se confina a uma ideia de subsunção normativa, por mais sofisticada que venha a ser essa ideia, também se en-

\footnotetext{
${ }^{6}$ No original: "The only way in which one can make do without law, Deleuze suggests, is through a 'jurisprudence' - a practical creativity that belongs to cases and local situations - and yet jurisprudence does not work outside of laws in some sphere abstracted from the custom of legal principle. It requires all of these laws, legal principles, judgments, etc. to constitute the desert of its immanent mode of navigation". (Tradução livre).
} 
contra envolvida com as fontes formais do direito, encontra-se pelo menos uma visualização mais específica do que seria uma prática que foge à compreensão que tinha Warat dos aspectos formalistas que envolviam as considerações das primeiras concepções epistemológicas presentes na teoria do direito.

Em síntese, a contribuição de Deleuze/Guattari ao projeto de Warat contempla as seguintes questões. Primeiro, eliminando a ideia de uma epistemologia jurídica pensada em termos de metalinguagem em favor de uma abordagem que considera os desdobramentos sucessivos da linguagem jurídica em meio aos múltiplos processos dinâmicos que constituem e deformam os conceitos e as práticas jurídicas.

Segundo, ao mesmo tempo em que reconhece as especificidades de cada domínio, "borra" as fronteiras entre eles ao desconsiderar a origem e a finalidade desses devires. Terceiro, abre espaço para uma compreensão pragmática da linguagem jurídica em detrimento de uma apenas representativa, e com isso ressalta a produção de efeitos das técnicas e dos conceitos jurídicos em um determinado ambiente institucional: seja por conta desse ambiente, seja em virtude das suas demandas, os conceitos jurídicos atuam sobre o mundo, não apenas formam uma imagem dele. Por fim, embora se trate de uma questão subdesenvolvida ao longo desse artigo, a abordagem de Deleuze/Guattari também se encontra comprometida em pensar o poder a partir da semiótica, o que nos remete ao estudo dos performativos, sim, mas também à constituição das subjetividades e à relação desta constituição com outros domínios do social, como a economia:

A subjetivação como regime de signos ou forma de expressão remete a um agenciamento, isto é, a uma organização de poder que já funciona plenamente na economia, e que não vem se superpor a conteúdos ou a relações de conteúdos determinados como reais em última instância. (DELEUZE; GUATTARI, 2002, p. 85-86)

Relembra-se a maneira peculiar, ainda que nada original, com que Warat se apropria do conceito de cidadania. Não coloca em jogo a dimensão institucional, e também normativa, que usualmente acompanha o conceito: o direito ao voto, à representação popular, à participação política, etc. 
A preocupação se encontra em um estágio que precede a esses elementos, como a constituição de um imaginário social através de novas formas de subjetividade. Ora, essas formas de subjetividade estariam associadas - e Warat parece saber muito bem disso, embora não aprofunde a temática - com novos regimes de signo, o que engloba, mas de maneira alguma se restringe, à estrutura normativa fornecida pelo ordenamento jurídico positivo.

Já não se está pensando uma criação que possui um centro específico, seja ele a atividade dos juízes ou o ente estatal, como também escapa a uma determinação a priori. Não se confunde com discricionariedade, e menos ainda com as atividades usuais do poder legislativo: trata-se antes de uma criação que foge, que escapa às determinações normativas para, a partir delas, produzir continuamente algo inusitado e que confronta as antigas expectativas dos juristas e da sociedade. Trata-se de um excesso que, operando através do normativo, excede-o sempre. Uma meditação profunda sobre o conhecimento jurídica necessita fazer as pazes com o substrato caótico e inusitado que existe na ordem e naquilo que é mais usual.

\section{Conclusão}

Tomando como fio condutor as reflexões críticas de Luis Alberto Warat às tendências formalistas na epistemologia jurídica e a sua incursão por uma semiótica jurídica que se pretende crítica daquelas tendências, opera-se uma aproximação com a filosofia de Deleuze/Guattari, com ênfase na obra Mil Platôs. A ideia da aproximação seria a de observar como a filosofia dos autores poderia contribuir às considerações de Warat.

Nossa preocupação inicial foi determinar exatamente aquilo que Warat está confrontando. A ideia de formalismo, que não deve ser de maneira alguma associada à concepção mais usual de formalismo jurídico (SCHAUER, 1988), remete a uma epistemologia concebida em termos de metalinguagem comprometida com a validade, a justificação e a legitimação de um outro campo de saber e que ela toma como seu objeto. Em certo sentido, trata-se de uma concepção transcendental da epistemologia. 
Warat enxerga esse tipo de pretensão sendo desenvolvida ao menos na teoria pura do direito de Kelsen. Ele e Deleuze/Guattari, por razões e argumentos diversos, rechaçam esse papel tanto para a epistemologia (o caso de Warat) quanto para a filosofia de um modo mais amplo (o caso de Deleuze/Guattari).

A distinção estabelecida por Warat entre o discursivo e o extradiscursivo pode ser aprofundada quando a complementamos com um estudo dos performativos no contexto institucional do direito, especialmente na maneira como o direito constrói - mas também poderia-se dizer percebe - ao seu modo e com as suas características específicas, uma realidade que lhe externa. Uma vez que as categorias jurídicas não são concebidas como elementos voltados tão somente para a representação de uma realidade exterior àquela do direito, também intervindo sobre essa realidade na medida em que se mostram elementos de soluções viáveis e que alteram estado de coisas, é preciso pensar como os signos abrem espaço para novos modos de existência e subjetividade a partir desse contexto jurídico.

A maneira pela qual Warat concebe o extradiscursivo enfatiza a pluralidade de mecanismos e centros de produção que concorrem para a composição e organização do discurso jurídico. A ideia não é apenas constatar que um conhecimento desse campo passa por considerações de natureza interdisciplinar, o que por si só seria importante para problematizar qualquer projeto voltado para determinar a especificidade do fenômeno jurídico, mas apontar também as variadas maneiras com que o direito pode - e é - continuamente reconstruído no espaço social. Por isso, fez-se menção ao modo como Warat pensa a cidadania.

Esse último ponto seria, de fato, aquele que melhor estabelece uma aproximação entre as duas perspectivas discutidas: elas não realizaram incursões pela semiótica na busca pela delimitação de um espaço em que seria possível conceber, em termos científicos, o conhecimento jurídico, mas para pensar novos conceitos e abordagens que permitissem experiências inusitadas no campo jurídico. Isso está mais claramente em Deleuze/ Guattari do que em Warat. Ambos são pensadores do estranhamento e do inabitual, e concebem a problematização não como a busca pela solução 
de uma questão complexa, mas o seu desenvolvimento através de novos conceitos e perguntas inquietantes.

\section{Referências}

CONWAY, Jay. Gilles Deleuze: affirmation in philosophy. London: Palgrave Macmillan, 2010.

DELEUZE, Gilles; GUATTARI, Félix. Mil Platôs. 3. ed. São Paulo: Editora 34, 2004. v. 1.

DELEUZE, Gilles; GUATTARI, Félix. Mil Platôs. 2. ed. São Paulo: Editora 34, 2002. v. 2.

DELEUZE, Gilles; GUATTARI, Félix. O Que é a Filosofia? 2. ed. São Paulo: Editora 34, 1997.

DELEUZE, Gilles. Negotiations: 1972-1990. New York, NY: Columbia University Press, 1995.

MACLEAN, James. Rethinking Law as Process: Creativity, Novelty, Change. London: Routledge, 2012.

MURRAY, Jamie. Deleuze \& Guattari's Intensive \& Pragmatic Semiotic of Emergent Law. International Journal for the Semiotics of Law, [S.l.], (Revue Internationale de Sémiotique Juridique), v. 20, p. 7-32, 2007.

MUSSAWIR, Edward. Jurisdiction in Deleuze: the Expression and Representation of Law. London: Routledge, 2011.

PHILIPPOPOULOS-MIHALOPOULOS, Andreas. Critical Autopoiesis: The Environment of the Law. Westminster School of Law, London, England, p. 45-62, Dec., 2011. Disponível em: http://ssrn.com/ abstract $=1968385$. Acesso em: 3 fev. 2020.

PHILIPPOPOULOS-MIHALOPOULOS, Andreas. Law, Space, Bodies: The Emergence of Spatial Justice. In: SUTTER, Laurent de; MCGEE, Kyle. Deleuze and Law. Edinburgh: Edinburgh University Press, 2012. p. $90-110$. 
SCHAUER, Frederick. Formalism. The Yale Law Journal, [S.l.], v. 97, n. 4, p. 509-548, mar., 1988,

SCHUILENBURG, Marc. Institutions and Interactions: On the Problem of the Molecular and Molar. In: SUTTER, Laurent de; MCGEE, Kyle. Deleuze and Law. Edinburgh: Edinburgh University Press, 2012. p. 111131.

SILVA, Alexandre Rocha da et al. Deleuze e a Semiótica Crítica.

Semeiosis: Semiótica e Transdiciplinaridade em revista, [S.l.], $1^{\circ}$ sem., p. 1-15, 2013.

WARAT, Luis Alberto. Introdução Geral ao Direito I: interpretação das Leis - temas para uma Reformulação. 2. ed. Porto Alegre: SAFE, 1995.

WARAT, Luis Alberto. Introdução Geral ao Direito II: a Epistemologia Jurídica da Modernidade. 2. ed. Porto Alegre: SAFE, 2002.

WARAT, Luis Alberto. O Direito e sua linguagem. 2. ed. Porto Alegre: SAFE, 1994.

\section{Leonardo Monteiro Crespo de Almeida}

E-mail: leonardoalmeida326@gmail.com

https://orcid.org/0000-0001-5742-3344

Doutor e Mestre em Teoria do Direito pela Universidade Federal de Pernambuco (UFPE). Bacharel em Filosofia pela mesma instituição.

Endereço profissional: Av. Dr. Malaquias, n. 255, Graças, Recife, PE. CEP: 52050-060. 